\title{
Electrosynthesis of Adiponitrile with a Rotating Cylindrical Electrode
}

Wei-Fan Huang, Ming-Chang Yang*

Department of Chemical Engineering, National Cheng Kung University, 1 University Rd., Tainan, 70101 Taiwan.

*Corresponding author. e-mail address: mcyang@mail.ncku.edu.tw Phone: 886-6-2757575 ext. 62666 
(a)

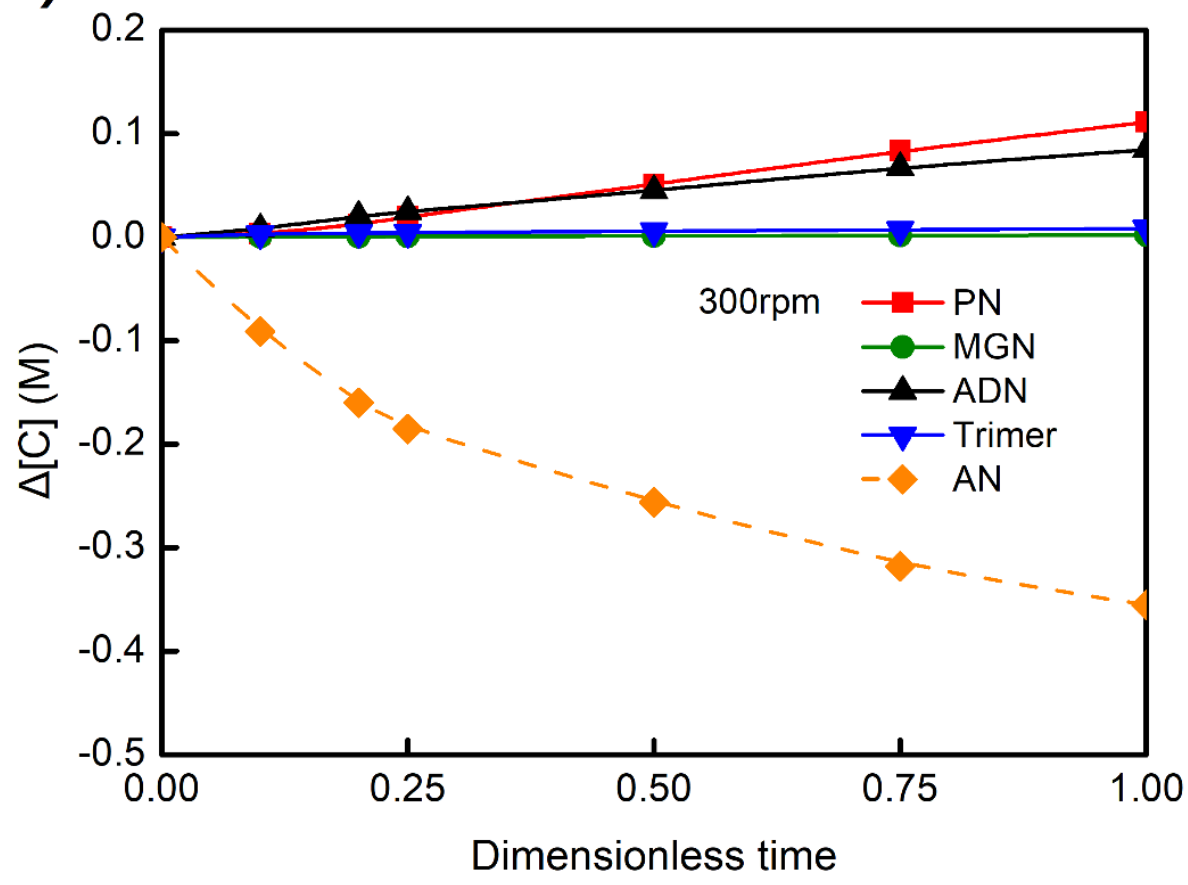

(b)

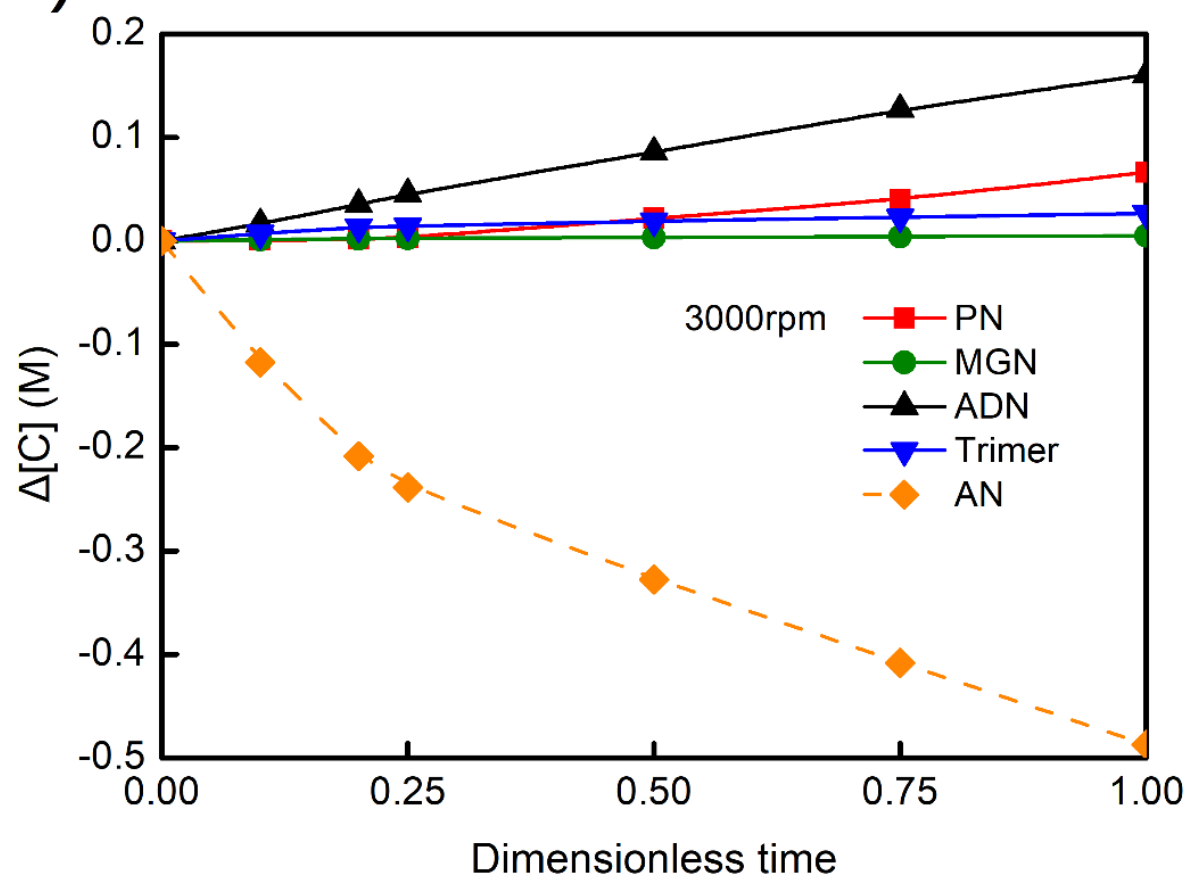

Figure S1. Concentration changes of PN, MGN, ADN, Trimer and AN along dimensionless time at (a) $300 \mathrm{rpm}$ and (b) $3000 \mathrm{rpm}$. ri $=4$, ro $=24$ $\mathrm{mm}$ and $\mathrm{H}=10 \mathrm{~mm}$. 


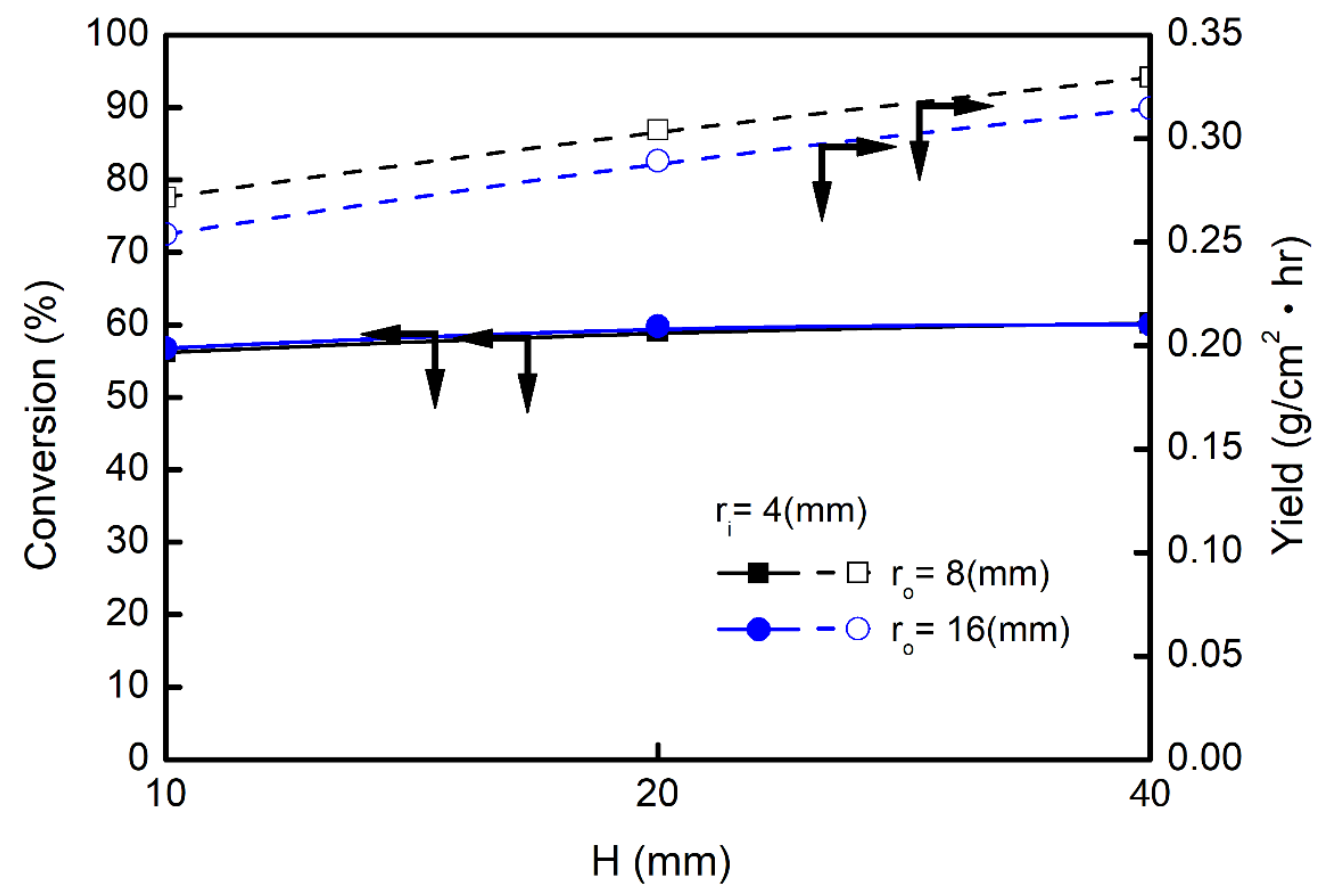

Figure S2. Effects of the electrode length on the conversion and the yield with a dimensionless time of 0.5 at $3000 \mathrm{rpm}$. $\mathrm{ri}=4 \mathrm{~mm}$, and ro $=8$ and $16 \mathrm{~mm}$. 